\title{
Research on small-scale structures of ice particle density and electron density in the mesopause region
}

\author{
Ruihuan Tian ${ }^{1,2}$, Jian $\mathrm{Wu}^{2}$, Jinxiu $\mathrm{Ma}^{3}$, Yonggan Liang ${ }^{1,2}$, Hui $\mathbf{L i}^{1,2}$, Chengxun Yuan ${ }^{1,4}$, Yongyuan Jiang ${ }^{1}$, and \\ Zhongxiang Zhou ${ }^{1,4}$ \\ ${ }^{1}$ Department of Physics, Harbin Institute of Technology, Harbin 150001, China \\ ${ }^{2}$ National Key Laboratory of Electromagnetic Environment (LEME), China Research Institute of Radio \\ Wave Propagation, Beijing 102206, China \\ ${ }^{3}$ Department of Modern Physics, University of Science and Technology of China, Hefei 230026, China \\ ${ }^{4}$ Center of Space Environment of Polar Regions, Harbin Institute of Technology, Harbin 150001, China
}

Correspondence: Hui Li (lihui_2253@163.com) and Chengxun Yuan (yuancx@hit.edu.cn)

Received: 19 January 2019 - Discussion started: 5 March 2019

Revised: 13 October 2019 - Accepted: 25 October 2019 - Published: 5 December 2019

\begin{abstract}
The formation of ice particle density irregularities with a meter scale in the mesopause region is explored in this paper by developing a growth and motion model of ice particles based on the motion equation of a variable mass object. The growth of particles by water vapor adsorption and the action of gravity and the neutral drag force on particles are considered in the model. The evolution of the radius, velocity, and number density of ice particles is then investigated by solving the growth and motion model numerically. For certain nucleus radii, it is found that the velocity of particles can be reversed at a particular height, leading to a local gathering of particles near the boundary layer, which then forms smallscale ice particle density structures. The spatial scale of the density structures can be affected by vertical wind speed, water vapor density, and altitude, and it remains stable as long as these environmental parameters do not change. The influence of the stable small-scale structures on electron and ion density is further calculated by a charging model, which considers the production, loss, and transport of electrons and ions, along with dynamic particle charging processes. Results show that the electron density is anti-correlated to the charged ice particle density and ion density for particles with radii of $11 \mathrm{~nm}$ or less due to plasma attachment by particles and plasma diffusion. This finding is in accordance with most rocket observations. The small-scale electron density structures created by small-scale ice particle density irregularities can produce the polar mesosphere summer echo (PMSE) phenomenon.
\end{abstract}

\section{Introduction}

Polar mesosphere summer echoes (PMSEs) are strong radar echoes from the polar mesopause in summer (Rapp and Lübken, 2004). One of the features of the PMSEs is that the spectral widths of echoes are much narrower than that of incoherent scatter due to the Brownian movement of electrons (Röttger, et al., 1988, 1990). It has been proposed that the PMSEs are caused by radar waves coherently scattered by irregularities in the refractive index, which are mainly determined by electron density (Rapp and Lübken, 2004). The efficient scattering occurs when the spatial scale of electron density structures is half of the radar wavelength, which is called the Bragg scale. The scale is approximately $3 \mathrm{~m}$ for typical VHF radars (Rapp and Lübken, 2004). In the ECT02 rocket campaign (Lübken et al., 1998), a sounding rocket with electron probes detected electron density irregularities in the order of meters during a simultaneous observation of the PMSEs, providing a compelling argument that small-scale electron density structures can indeed create strong radar echoes.

A large amount of research indicates that small-scale ice particle density irregularities in the PMSE region play a key role in creating and maintaining small-scale structures of electron density (Chen and Scales, 2005; Lie-Svendsen et al., 2003; Mahmoudian and Scales, 2013; Rapp and Lübken, 2003; Scales and Ganguli, 2004). Markus Rapp and FranzJosef Lübken investigated electron diffusion in the vicinity of charged particles (Rapp and Lübken, 2003). They developed 
coupled diffusion equations for electrons, charged aerosol particles, and positive ions subject to the initial condition of anti-correlated perturbations in charged aerosol and electron distributions. The results illustrate that the perturbations of electron density are anti-correlated to that of the negatively charged aerosol particles and positive ions. Lie-Svendsen et al. studied the plasma response to imposed small-scale aerosol particle density perturbations (Lie-Svendsen et al., 2003). The results were consistent with the solution provided by Markus Rapp's model, in which particle density structures in the order of a few meters could lead to small-scale electron density perturbations due to electron attachment and ambipolar diffusion.

In the work mentioned above, aerosol particle density profiles were directly set as specific small-scale structures such as Gaussian, hyperbolic tangent, or sinusoidal. However, the formation mechanism of the small-scale particle density structures can contribute to a more comprehensive understanding of the PMSE phenomenon and is neglected in such studies. Kopnin et al. used dust acoustic solitons to explain the localized structures of the charged dust particles in the PMSE region (Kopnin et al., 2004), but the spatial scales of the obtained structures were much smaller than the observed scale and wavelength of VHF radar. Therefore, the formation mechanism of small-scale structures in the PMSE region remains not clear.

In the polar mesopause region, neutral airflow moves upward (Garcia and Solomon, 1985). The ice particles are subject to upward neutral drag force and downward gravity, and they grow by absorbing water vapor simultaneously. In addition, the size of initial condensation nuclei has a certain distribution. These factors can cause complex trajectories of ice particles and result in an inhomogeneous distribution of particle number density, leading to small-scale structures of electron density. This may be an important mechanism that can produce a PMSE phenomenon. However, few studies have explored the formation process of small-scale ice particle structures from the perspective of ice particle growth and movement.

A particle growth and motion model is thus developed in this paper to describe the evolution of the ice particle radius, velocity, and density distribution in the mesopause region. The growth of particles is based on the collision and adsorption process of condensation nuclei and water vapor. The particle movement is predominantly controlled by the gravity and the neutral drag force. With the obtained ice particle density structures, the corresponding electron and ion densities are calculated based on a charging model, which includes the continuity equations for ice particles with various charges and ions, the momentum equation for ions and electrons, and the quasi-neutral condition.

\section{Model}

Equations for the growth and motion model of condensation nuclei and the charging model of ice particles are detailed in this section.

The simulation is carried out at a summer polar mesopause region between 80 and $90 \mathrm{~km}$, where the water vapor carried by neutral gas is determined to move upwards at a constant speed (Garcia and Solomon, 1985). It is assumed that micrometeorites enter the study region at a certain flux from the upper boundary, and volcanic ash or particles ejected by the aircraft rise into the region from the lower boundary. These grains serve as condensation cores. When the temperature is lower than the frost point (Körner and Sonnemann, 2001), water vapor molecules that touch the surface of the grains due to thermal motion can easily condense into ice. In this process, condensation cores become ice particles and continue to grow. In this article, only the growth, motion, and charging process of particles inside the condensation layer are discussed, and only the vertical transport of particles and plasma is considered as the horizontal gradients of transport parameters are much smaller comparatively (Lie-Svendsen et al., 2003).

For growing ice particles, the dynamic equation for a variable mass object is applied.

$m_{\mathrm{d}} \frac{\mathrm{d} u_{\mathrm{d}}}{\mathrm{d} t}+\left(u_{\mathrm{d}}-u\right) \frac{\mathrm{d} m_{\mathrm{d}}}{\mathrm{d} t}=m_{\mathrm{d}} g-\mu_{\mathrm{dn}} m_{\mathrm{d}}\left(u_{\mathrm{d}}-u\right)+q_{\mathrm{d}} E$,

where $m_{\mathrm{d}}, u_{\mathrm{d}}$, and $q_{\mathrm{d}}$ are the mass, velocity, and charge of ice particles, respectively, $u$ is the velocity of neutral gas, $g$ is gravitational acceleration, $\mu_{\mathrm{dn}}$ is the collision frequency between ice particles and gas, and $E$ is the electric field. The electric force has a trivial effect on the motion of ice particles because the charge-mass ratio of particles is usually very small (Jensen and Thomas, 1988; Pfaff et al., 2001). The inertial term is also negligible as its magnitude is much smaller than gravity (Garcia and Solomon, 1985).

The water vapor is supersaturated in the polar mesopause region (Lübken, 1999), and it is assumed that the size of condensation nuclei is larger than the condensation critical size, so stable growth of ice particles will continue when water molecules collide with particles during thermal motion. Ignoring reverse processes such as sublimation, the mass change rate of ice particles is

$\frac{\mathrm{d} m_{\mathrm{d}}}{\mathrm{d} t}=\mu_{\mathrm{wd}} m_{\mathrm{w}}$.

The collision frequency between water vapor and ice particles is $\mu_{\mathrm{wd}}=n_{\mathrm{w}} \pi r_{\mathrm{d}}^{2} v_{\mathrm{w}}$ based on the hard-sphere collision model (Lieberman and Lichtenberg, 2005), in which $m_{\mathrm{w}}, n_{\mathrm{w}}$, and $v_{\mathrm{w}}$ are the mass, number density, and thermal velocity of water molecules, respectively. 

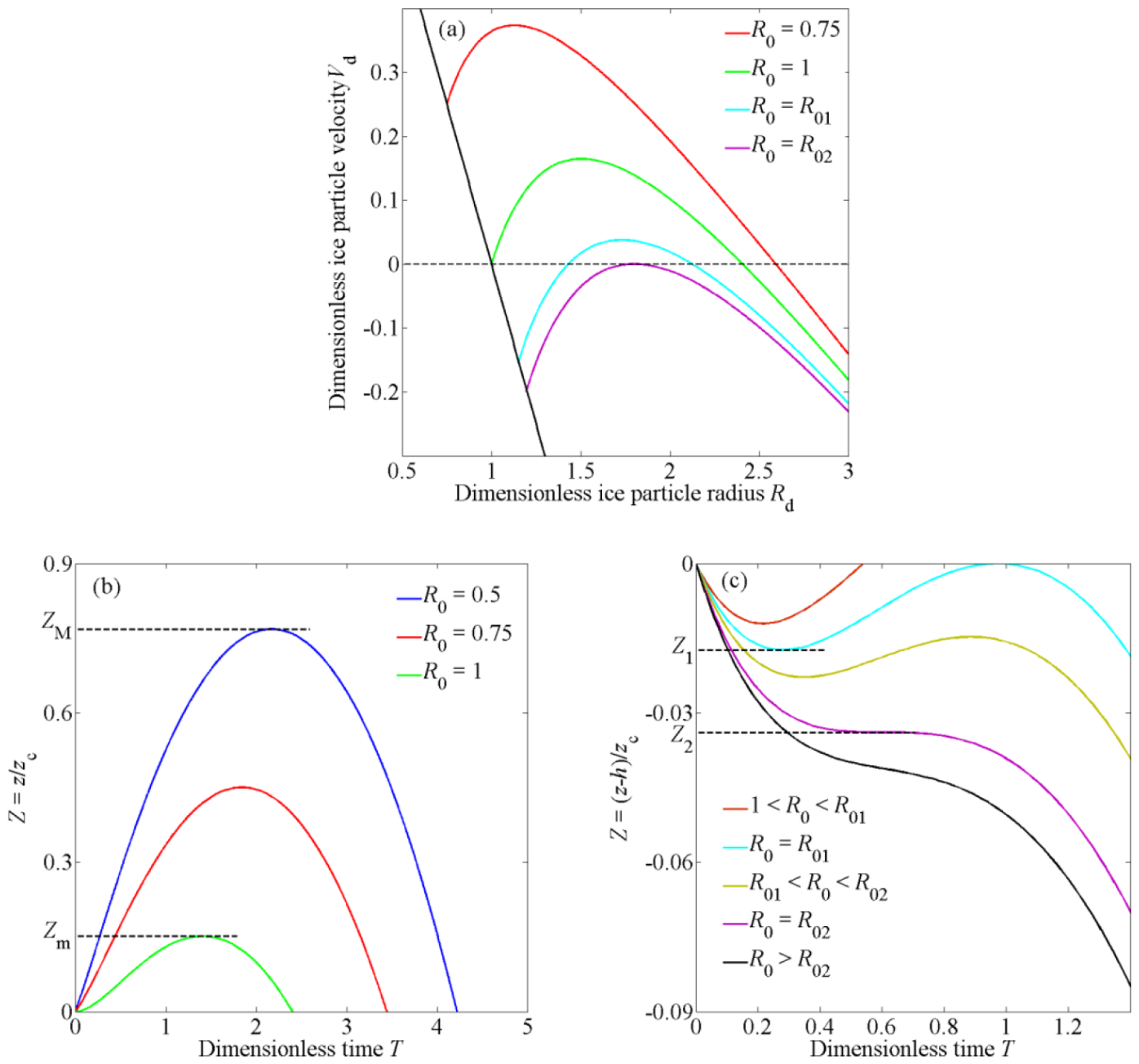

Figure 1. (a) Dependence of the ice particle velocity on radius for different initial nucleus radii. The black solid line $V_{d 0}=1-R_{0}$ represents the relation between the initial particle velocity and the initial particle radius. (b) Movement curves of ice particles near the lower boundary. (c) Movement curves of ice particles near the upper boundary.

The collision frequency between air molecules and ice particles in the neutral drag force term is (Schunk, 1977)

$\mu_{\mathrm{dn}}=\frac{8}{3 \sqrt{\pi}} \frac{n_{\mathrm{n}} m_{\mathrm{n}}}{m_{\mathrm{d}}+m_{\mathrm{n}}} \sqrt{\frac{2 k_{\mathrm{B}} T_{\mathrm{g}}\left(m_{\mathrm{d}}+m_{\mathrm{n}}\right)}{m_{\mathrm{d}} m_{\mathrm{n}}}} \pi\left(r_{\mathrm{d}}+r_{\mathrm{n}}\right)^{2}$

where $n_{\mathrm{n}}, m_{\mathrm{n}}$, and $r_{\mathrm{n}}$ are the number density, mean molecule mass, and effective radius of neutral molecule, respectively, and $T_{\mathrm{g}}$ is the gas temperature. The neutral molecule mass $m_{\mathrm{n}}$ is assumed to be $28.96 m_{u}$, in which $m_{u}$ is the proton mass.

According to Eq. (1) the velocity of ice particles is obtained as

$u_{\mathrm{d}}=u+\frac{m_{\mathrm{d}}}{\mu_{\mathrm{dn}} m_{\mathrm{d}}+\mu_{\mathrm{wd}} m_{\mathrm{w}}} g$.

On the basis that $n_{\mathrm{w}} \ll n_{\mathrm{n}}$ (Seele and Hartogh, 1999), $m_{\mathrm{w}} \ll$ $m_{\mathrm{d}}, m_{\mathrm{n}} \ll m_{\mathrm{d}}, r_{\mathrm{n}} \ll r_{\mathrm{d}}, v_{\mathrm{n}} \sim v_{\mathrm{w}}$ and taking vertical up to be the positive direction, the velocity of ice particles is simpli- fied as

$u_{\mathrm{d}}=u-g / \mu_{\mathrm{dn}}$

Ice particles are composed of condensation nuclei and the attached ice. The mass of a single ice particle is

$m_{\mathrm{d}}=\frac{4}{3} \pi r_{0}^{3} \rho_{0}+\frac{4}{3} \pi\left(r_{\mathrm{d}}^{3}-r_{0}^{3}\right) \rho_{\mathrm{d}}$,

where $r_{0}$ and $\rho_{0}$ are the initial radius and mass density of condensation nuclei and $\rho_{\mathrm{d}}$ is the mass density of ice.

Based on the expressions of $m_{\mathrm{d}}$ and $\mu_{\mathrm{dn}}$, the relation between ice particle velocity and radius is

$u_{\mathrm{d}}=u-\frac{g}{n_{\mathrm{n}} m_{\mathrm{n}} v_{\mathrm{n}}}\left[\rho_{\mathrm{d}} r_{\mathrm{d}}+\left(\rho_{0}-\rho_{\mathrm{d}}\right) \frac{r_{0}^{3}}{r_{\mathrm{d}}^{2}}\right]$.

At the boundaries of the condensation region $r_{\mathrm{d}}=r_{0}$, the initial velocity of condensation nuclei is

$u_{\mathrm{d} 0}=u\left(1-r_{0} / r_{\mathrm{c}}\right)$, 

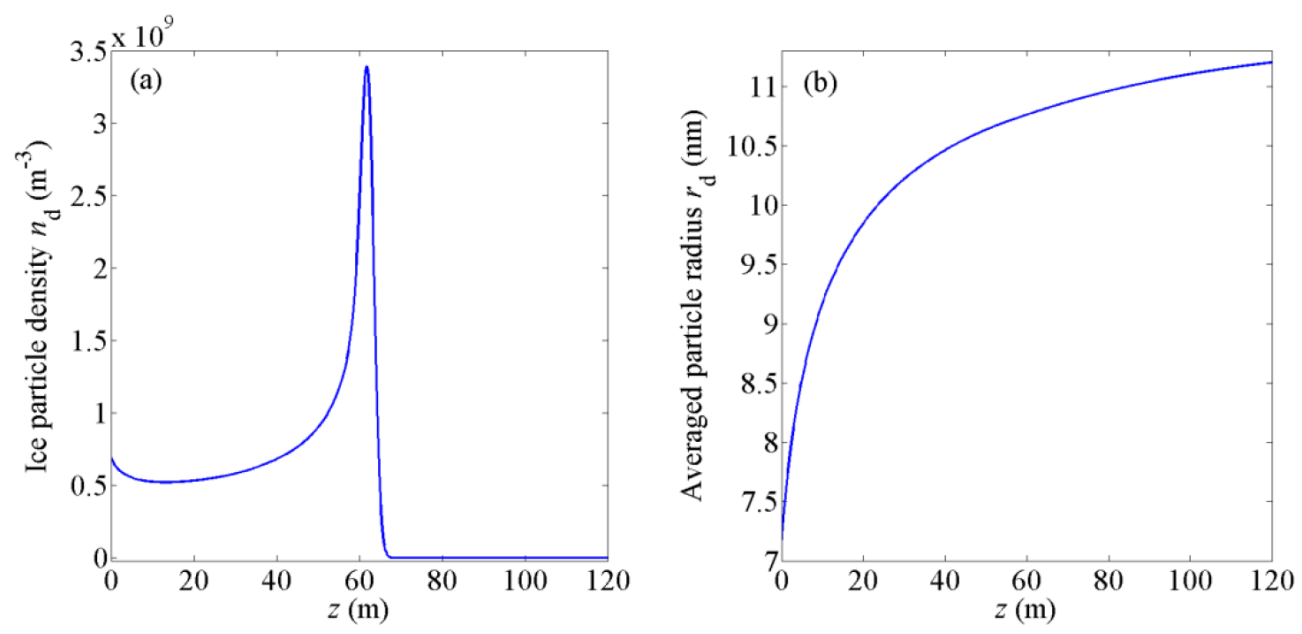

Figure 2. Distribution of (a) ice particle density and (b) averaged particle radius near the lower boundary of the condensation layer.

where $r_{\mathrm{c}}$ is the critical radius of

$r_{\mathrm{c}}=n_{\mathrm{n}} m_{\mathrm{n}} v_{\mathrm{n}} u /\left(g \rho_{0}\right)$.

When the radius of condensation nuclei is $r_{0}>r_{\mathrm{c}}$, gravity is larger than the neutral drag force of $v_{\mathrm{d} 0}<0$ and particles move downwards. Otherwise, particles move upwards.

Based on the relation between $m_{\mathrm{d}}$ and $r_{\mathrm{d}}$, the change rate of ice particle radius is

$\frac{\mathrm{d} r_{\mathrm{d}}}{\mathrm{d} t}=\frac{1}{4} \frac{n_{\mathrm{w}} m_{\mathrm{w}} v_{\mathrm{w}}}{\rho_{\mathrm{d}}}=c$.

It can be clearly observed that the ice particle radius increases linearly with time.

$r_{\mathrm{d}}=r_{0}+c t$

The particle trajectory can then be obtained by the following integral:

$z-z_{0}=\int_{0}^{t} u_{\mathrm{d}} \mathrm{d} t=c^{-1} \int_{r_{0}}^{r_{\mathrm{d}}} u_{\mathrm{d}} \mathrm{d} r_{\mathrm{d}}$

where $z_{0}$ is the reference height where condensation nuclei enter the studied region. In this work $z_{0}=0$ is set at the lower boundary, and $z_{0}=h$ is set at the upper boundary, where $h$ is the distance between the two boundaries.

It is assumed that the condensation nucleus radius ranging from $r_{0 \min }$ to $r_{0 \max }$ has a certain distribution function $f\left(r_{0}\right)$. The density of condensation nuclei with a radius in the small range is $r_{0} \rightarrow r_{0}+\mathrm{d} r_{0}$ is $\operatorname{dn}\left(r_{0}\right)=f\left(r_{0}\right) \mathrm{d} r_{0}$, and their velocity is $u_{\mathrm{d} 0}$. When these particles arrive at height $z$, their radius increases to $r_{\mathrm{d}}\left(r_{0}, z\right)$, the corresponding number density turns into $\operatorname{dn}\left(r_{0}, z\right)$, and the velocity becomes $u_{\mathrm{d}}\left(r_{0}\right.$, $z)=u_{\mathrm{d}}\left[r_{0}, r_{\mathrm{d}}\left(r_{0}, z\right)\right]$. According to the particle conservation law,

$u_{\mathrm{d} 0} \mathrm{~d} n\left(r_{0}\right)=u_{\mathrm{d}}\left(r_{0}, z\right) \mathrm{d} n\left(r_{0}, z\right)$.
The number density of ice particles at height $z$ can then be obtained by

$n_{\mathrm{d}}(z)=\int \mathrm{dn}\left(r_{0}, z\right)=\int_{r_{0 \text { min }}}^{r_{0} \max } \frac{u_{\mathrm{d} 0} f\left(r_{0}\right)}{u_{\mathrm{d}}\left(r_{0}, z\right)} \mathrm{d} r_{0}$.

The averaged ice particle radius at height $z$ is

$\bar{r}_{\mathrm{d}}(z)=\frac{\int r_{\mathrm{d}}(z) \mathrm{dn}\left(r_{0}, z\right)}{n_{\mathrm{d}}(z)}$.

By integrating all condensation nucleus radii, a stable distribution of $n_{\mathrm{d}}$ and $r_{\mathrm{d}}$ can be obtained. The particles continue to enter and leave the condensation region, and as long as the external environment does not change, the distribution of particle density and radius will remain unchanged. The influence of these stable $n_{\mathrm{d}}$ and $r_{\mathrm{d}}$ profiles on electron and ion density is then calculated.

Considering ionization, electron-ion recombination, and ion loss on ice particles, the continuity equation of ion density can be written as

$\frac{\partial n_{\mathrm{i}}}{\partial t}+\frac{\partial\left(n_{\mathrm{i}} u_{\mathrm{i}}\right)}{\partial z}=Q-\alpha n_{\mathrm{i}} n_{\mathrm{e}}-D^{+} n_{\mathrm{i}}$.

Ignoring gravity, the drift velocity of ions $u_{\mathrm{i}}$ is determined by

$u_{\mathrm{i}}=\frac{e E}{m_{\mathrm{i}} \mu_{\mathrm{in}}}-\frac{k_{\mathrm{B}} T_{\mathrm{g}}}{m_{\mathrm{i}} \mu_{\mathrm{in}}} \frac{1}{n_{\mathrm{i}}} \frac{\partial n_{\mathrm{i}}}{\partial z}$.

The electric field $E$ is predominantly determined by the electron density gradient because the diffusion coefficient and mobility of electrons are much larger than that of ions.

$E=-\frac{k_{\mathrm{B}} T_{\mathrm{g}}}{e} \frac{1}{n_{\mathrm{e}}} \frac{\partial n_{\mathrm{e}}}{\partial z}$

In the typical PMSE layer, there are several kinds of ions carrying one unit positive charge: $\mathrm{N}_{2}^{+}, \mathrm{O}_{2}^{+}, \mathrm{NO}^{+}$, and 

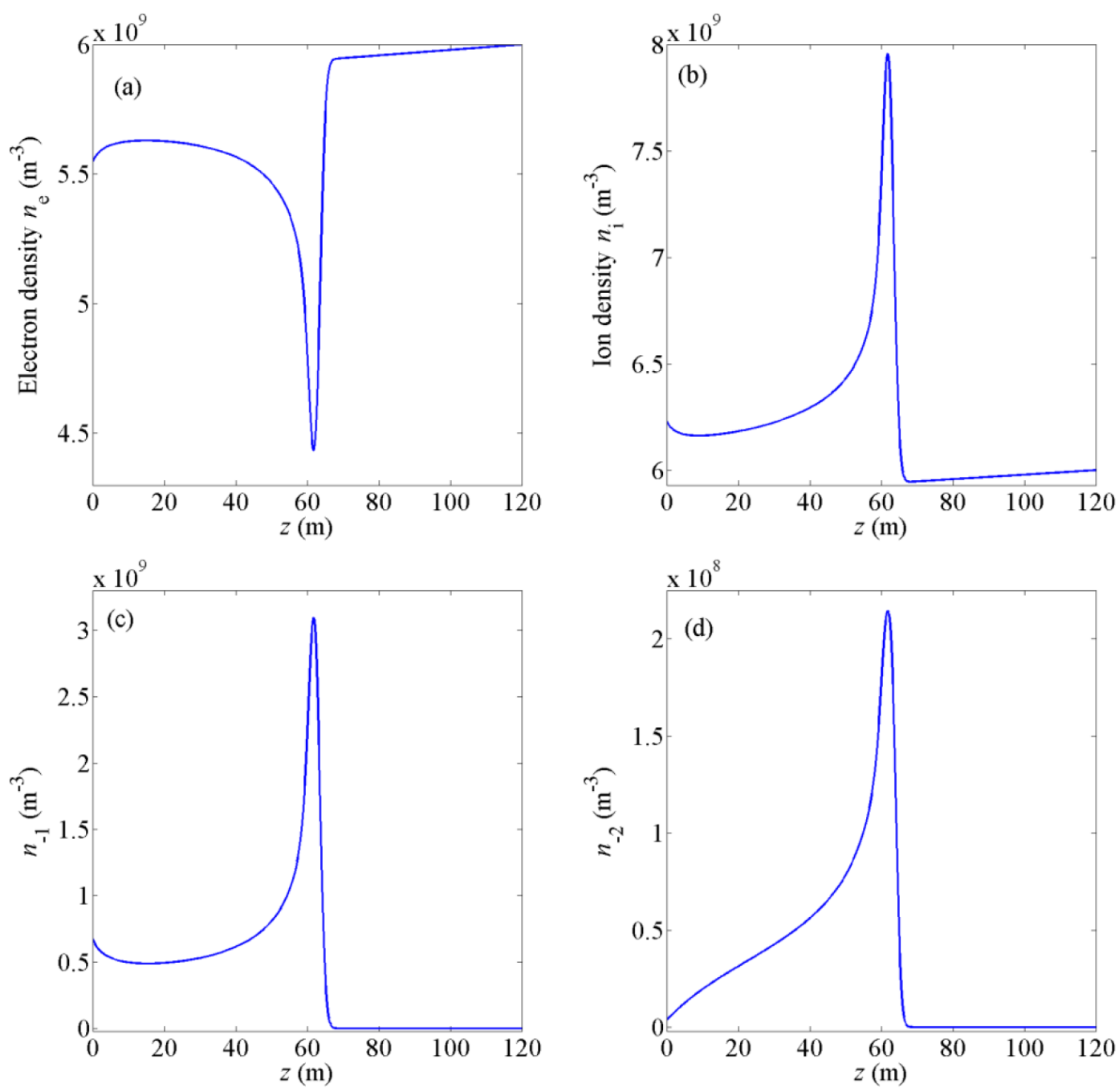

Figure 3. Number density distribution of (a) electrons $n_{\mathrm{e}}$, (b) ions $n_{\mathrm{i}}$, (c) particles carrying one negative charge $n_{-1}$, and (d) particles carrying two negative charges $n_{-2}$ near the lower boundary of the condensation layer at $t=1000 \mathrm{~s}$.

$\mathrm{H}^{+}\left(\mathrm{H}_{2} \mathrm{O}\right)_{n}$. As specified by Reid (Reid, 1990), the averaged ion parameters $n_{\mathrm{i}}, m_{\mathrm{i}}$, and $T_{\mathrm{g}}$ are applied to describe the density, mass, and temperature of ions, respectively, and the averaged ion mass $m_{\mathrm{i}}$ is set as $50 m_{u}$ at $85 \mathrm{~km}$ altitude. According to the theory of Hill and Bowhill (1977), the ion-neutral collision frequency is

$$
\begin{aligned}
& \mu_{\text {in }}=2.6 \times 10^{-15} n_{\mathrm{n}}\left(0.78 \frac{28}{M_{\mathrm{i}}+28} \sqrt{1.74 \frac{M_{\mathrm{i}}+28}{28 M_{\mathrm{i}}}}\right. \\
& +0.21 \frac{32}{M_{\mathrm{i}}+32} \sqrt{1.57 \frac{M_{\mathrm{i}}+32}{32 M_{\mathrm{i}}}} \\
& \left.+0.01 \frac{40}{M_{\mathrm{i}}+40} \sqrt{1.64 \frac{M_{\mathrm{i}}+40}{40 M_{\mathrm{i}}}}\right)
\end{aligned},
$$

where $M_{\mathrm{i}}=m_{\mathrm{i}} / m_{u}$.

The production rate for ions and electrons $Q$ is chosen to be $3.6 \times 10^{7} \mathrm{~m}^{-3} \mathrm{~s}^{-1}$, and the electron-ion recombination coefficient $\alpha$ is set as $10^{-12} \mathrm{~m}^{3} \mathrm{~s}^{-1}$ (Lie-Svendsen et al., 2003). The undisturbed density of ions and electrons is $n_{0}=6 \times 10^{9} \mathrm{~m}^{-3}$. The loss coefficient of ions on ice parti- cles is $D^{+}=\Sigma n_{q} \nu_{\mathrm{i}, q}$, where $n_{q}$ is the number density of the $q$-charged ice particles and $v_{\mathrm{i}, q}$ represents the capture rate of ions by ice particles with $q$ charges. According to the discrete charging model (Robertson and Sternovsky, 2008),

$v_{\mathrm{i}, q \leq 0}=\pi r_{\mathrm{d}}^{2} c_{\mathrm{i}}\left(1+C_{q} \sqrt{\frac{e^{2}}{16 \varepsilon_{0} k_{\mathrm{B}} T_{\mathrm{g}} r_{\mathrm{d}}}}+D_{q} \frac{e^{2}}{4 \pi \varepsilon_{0} k_{\mathrm{B}} T_{\mathrm{g}} r_{\mathrm{d}}}\right)$.

The particle radius $r_{\mathrm{d}}$ used here is the averaged radius $[U+$ $F 8 E 5] r_{\mathrm{d}}$, which is obtained using Eq. (15). The ion thermal velocity is $c_{\mathrm{i}}=\left(8 k_{\mathrm{B}} T_{\mathrm{g}} / \pi m_{\mathrm{i}}\right) ; k_{\mathrm{B}}$ is the Boltzmann constant; and $\varepsilon_{0}$ is the permittivity of a vacuum. The $C_{q}$ and $D_{q}$ are provided in Table 1 in the work of Robertson and Sternovsky (Robertson and Sternovsky, 2008), and the corresponding capture rates of electrons by ice particles (Robert- 


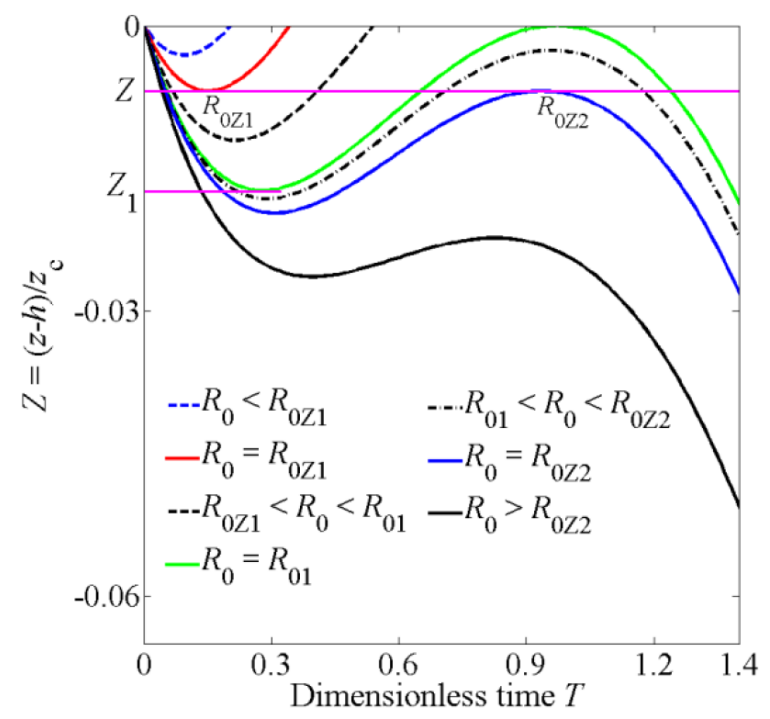

Figure 4. Movement curves of ice particles near the upper boundary. The particles with initial radius $R_{0 Z 1}$ move upward after turning back at the $Z$ height (the red line), and the particles with initial radius $R_{0 Z 2}$ move downward after turning back at $Z$ (the blue line).

son and Sternovsky, 2008) are denoted as

$$
\begin{aligned}
v_{\mathrm{e}, q \geq 0} & =\pi r_{\mathrm{d}}^{2} c_{\mathrm{e}}\left(1+C_{q} \sqrt{\frac{e^{2}}{16 \varepsilon_{0} k_{\mathrm{B}} T_{\mathrm{g}} r_{\mathrm{d}}}}+D_{q} \frac{e^{2}}{4 \pi \varepsilon_{0} k_{\mathrm{B}} T_{\mathrm{g}} r_{\mathrm{d}}}\right), \\
v_{\mathrm{e}, q<0} & =\pi r_{\mathrm{d}}^{2} \gamma^{2} c_{\mathrm{e}} \\
& \exp \left[-\frac{|q| e^{2}}{4 \pi \varepsilon_{0} k_{\mathrm{B}} T_{\mathrm{g}} r_{\mathrm{d}} \gamma}\left(1-\frac{1}{2 \gamma\left(\gamma^{2}-1\right)|q|}\right)\right] .
\end{aligned}
$$

The thermal velocity of electrons $c_{\mathrm{e}}=\left(8 k_{\mathrm{B}} T_{\mathrm{g}} / \pi m_{\mathrm{e}}\right)$ and the value of $\gamma$ for each $q$ is referenced from Natanson's paper (Natanson, 1960).

Although the distribution of total particle density $n_{\mathrm{d}}=$ $\Sigma n_{q}$ reaches a stable state under the action of gravity and neutral drag force, the number density of the $q$-charged ice particles $n_{q}$ is dynamic in the charging process. The continuity equation of $q$-charged ice particle density is

$$
\begin{aligned}
\frac{\partial n_{q}}{\partial t} & =n_{q+1} v_{\mathrm{e}, q+1} n_{\mathrm{e}}+n_{q-1} v_{\mathrm{i}, q-1} n_{\mathrm{i}} \\
& -\left(n_{q} v_{\mathrm{e}, q} n_{\mathrm{e}}+n_{q} v_{\mathrm{i}, q} n_{\mathrm{i}}\right)
\end{aligned} .
$$

According to previous research (Lie-Svendsen et al., 2003; Rapp and Lübken, 2001), it is assumed that a single particle carries two negative charges at the most, i.e., $q=-2,-1,0$, and +1 in this study.

According to typical parameters in the PMSE region (Rapp and Lübken, 2001), the plasma Debye length $\lambda_{\mathrm{D}}$ is estimated to be approximately $9 \mathrm{~mm}$, which is much smaller than the vertical spatial scale of the PMSE layer. Thus, the dusty plasma satisfies the quasi-neutral condition.

$n_{\mathrm{i}}+\sum_{q} q n_{q}=n_{\mathrm{e}}$
For simplicity, dimensionless parameters will be used in subsequent discussion.

$$
\begin{aligned}
& V_{\mathrm{d}}=v_{\mathrm{d}} / u, \quad \rho=\rho_{\mathrm{d}} / \rho_{0}, \quad R_{0}=r_{0} / r_{\mathrm{c}}, \quad R_{\mathrm{d}}=r_{\mathrm{d}} / r_{\mathrm{c}} \\
& T=t / t_{\mathrm{c}}, \quad Z=\left(z-z_{0}\right) / z_{\mathrm{c}},
\end{aligned}
$$

where $t_{\mathrm{c}}=r_{\mathrm{c}} / c$, which represents the time it takes for ice particles to grow from $r_{\mathrm{d}}$ to $r_{\mathrm{d}}+r_{\mathrm{c}}$, and $z_{\mathrm{c}}=u t_{\mathrm{c}}$ is the distance that neutral wind moves during the time $t_{\mathrm{c}}$.

The expression of dimensionless ice particle velocity is

$V_{\mathrm{d}}=1-\rho R_{\mathrm{d}}-(1-\rho) \frac{R_{0}^{3}}{R_{\mathrm{d}}^{2}}$.

The expressions of the dimensionless position coordinate of particles based on $T$ and $R_{\mathrm{d}}$ are

$$
\begin{aligned}
Z\left(R_{0}, T\right)= & T-\frac{1}{2} \rho T\left(T+2 R_{0}\right)-(1-\rho) R_{0}^{2} \frac{T}{T+R_{0}} \\
Z\left(R_{0}, R_{\mathrm{d}}\right) & =R_{\mathrm{d}}-R_{0}-\frac{1}{2} \rho\left(R_{\mathrm{d}}^{2}-R_{0}^{2}\right) \\
& +(1-\rho) R_{0}^{3}\left(\frac{1}{R_{\mathrm{d}}}-\frac{1}{R_{0}}\right) .
\end{aligned}
$$

The dimensionless number density and radius distribution of ice particles are

$$
\begin{aligned}
& n_{\mathrm{d}}(Z)=n_{0} \int_{R_{0 \text { min }}}^{R_{0 \max }} \frac{V_{\mathrm{d} 0} F\left(R_{0}\right)}{V_{\mathrm{d}}\left[R_{0}, R_{\mathrm{d}}\left(R_{0}, Z\right)\right]} \mathrm{d} R_{0}, \\
& \bar{R}_{\mathrm{d}}(Z)=\frac{n_{0}}{n_{\mathrm{d}}(Z)} \int_{R_{0 \text { min }}}^{R_{0 \text { max }}} \frac{R_{\mathrm{d}}(Z) V_{\mathrm{d} 0} F\left(R_{0}\right)}{V_{\mathrm{d}}\left[R_{0}, R_{\mathrm{d}}\left(R_{0}, Z\right)\right]} \mathrm{d} R_{0},
\end{aligned}
$$

where $n_{0}$ is the density of condensation cores at the boundary, and it is assumed to be $5 \times 10^{8} \mathrm{~m}^{-3}$ (Bardeen et al., 2008). The normalized radius distribution function $F\left(R_{0}\right)$ satisfies $\int_{R_{0 \text { min }}}^{R_{0 \max }} F\left(R_{0}\right) \mathrm{d} R_{0}=1$.

In subsequent calculations, parameters are taken in the atmospheric environment at an altitude of $85 \mathrm{~km}$. The number density of neutrals is $n_{n}=2.3 \times 10^{20} \mathrm{~m}^{-3}$ (Hill et al., 1999); the number density of water vapor is $n_{\mathrm{w}}=2.5 \times 10^{14} \mathrm{~m}^{-3}$ (Seele and Hartogh, 1999); the temperature is $T_{\mathrm{g}}=150 \mathrm{~K}$; the mass density of ice is $\rho_{\mathrm{d}}=1 \times 10^{3} \mathrm{~kg} \mathrm{~m}^{-3}$; the velocity of neutral wind is $u=3 \mathrm{~cm} \mathrm{~s}^{-1}$ (Garcia and Solomon, $1985)$; the mass density of condensation nucleus is $\rho_{0}=$ $2.7 \times 10^{3} \mathrm{~kg} \mathrm{~m}^{-3}$; and the growth rate of ice particles is $c \approx$ $7.8 \times 10^{-4} \mathrm{~nm} \mathrm{~s}^{-1}$. In this work, we only consider the growth and movement of condensation nuclei which fall from the upper boundary with the initial radius $r_{0}>r_{\mathrm{c}}$ and rise from the lower boundary with $r_{0} \leq r_{\mathrm{c}}$.

\section{Results and discussion}

\subsection{Speed and trajectory of ice particles}

The relation between $V_{\mathrm{d}}$ and $R_{\mathrm{d}}$ is illustrated in Fig. 1a, which shows that condensation nuclei with an initial radius 

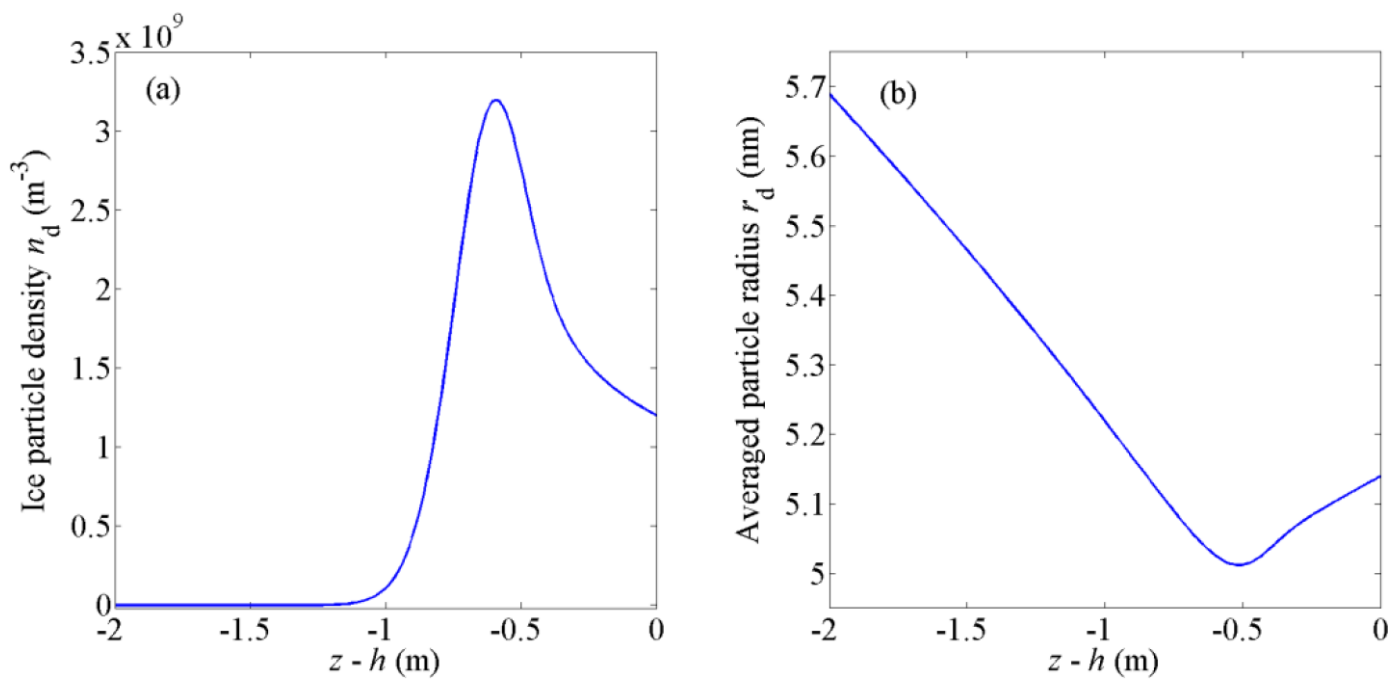

Figure 5. The distribution of (a) ice particle density and (b) the averaged particle radius near the upper boundary of the condensation layer.
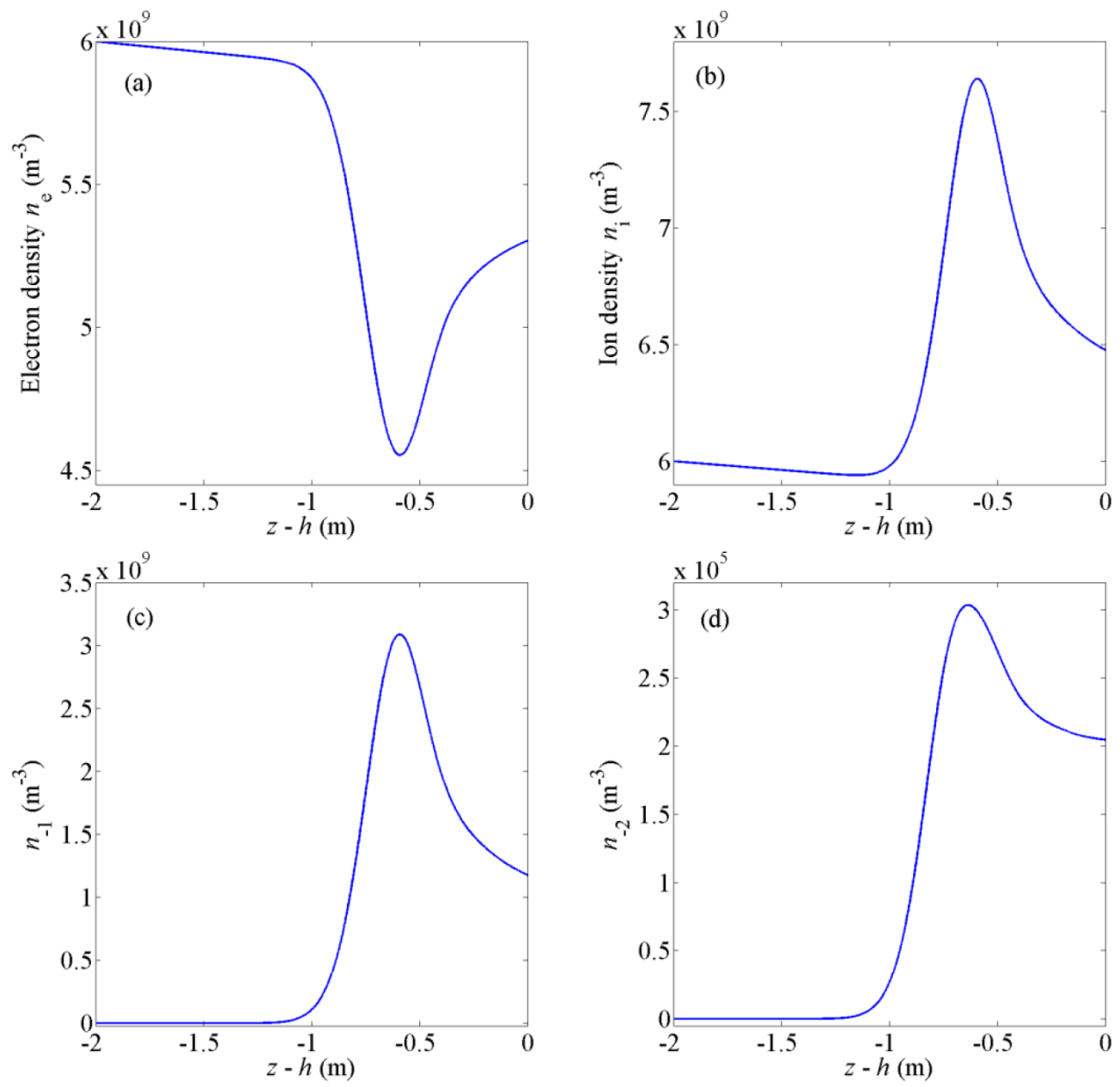

Figure 6. The number density distribution of (a) electrons, (b) ions, (c) particles carrying one negative charge, and (d) particles carrying two negative charges near the upper boundary of the condensation layer at $t=1000 \mathrm{~s}$. 

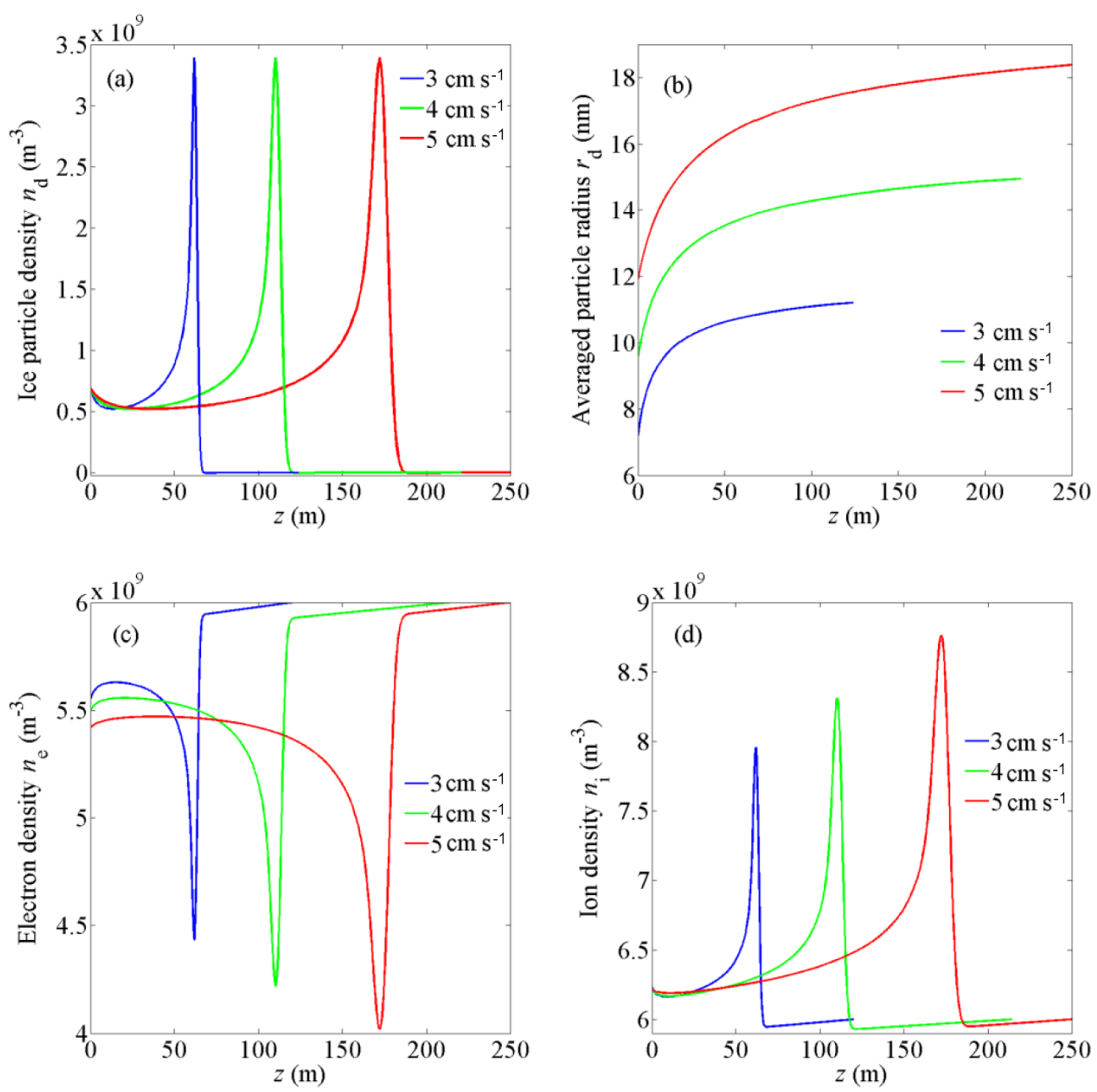

Figure 7. The distribution of (a) ice particle density, (b) the averaged particle radius, (c) electron density, and (d) ion density for various vertical wind speeds near the lower boundary of the condensation layer.

$R_{0} \leq 1$ rise into the PMSE region through the lower boundary, while particles with $R_{0}>1$ fall into the region from the upper boundary. At the beginning, the upward-moving particles accelerate and the downward particles decelerate due to $\partial V_{\mathrm{d}} / \partial R_{\mathrm{d}}=2-3 \rho>0$ when $R_{\mathrm{d}}=R_{0}$. Later, with the increase of $R_{\mathrm{d}}, \partial V_{\mathrm{d}} / \partial R_{\mathrm{d}}<0$, all particles will move with a downward acceleration, which makes them eventually move downward.

Figure $1 \mathrm{~b}$ shows the movement curves of ice particles near the lower boundary. These particles, with an initial radius $R_{0} \leq 1$ will rise into the condensation layer. With the collection of ice, the grains become larger and heavier, leading to their deceleration. The grains will then accelerate downward until they leave the condensation layer from the lower boundary. All particles rising from the lower boundary will retrace in the range $Z_{\mathrm{m}}<Z<Z_{\mathrm{M}}$. $Z_{\mathrm{m}}$ is the maximum height that particles with an initial radius $R_{0}=1$ can reach, and $Z_{\mathrm{M}}$ is the maximum height that particles with an initial ra- dius $R_{0}=R_{0 \min }=0.5$ can reach. Based on above parameters, $Z_{\mathrm{m}}=0.1512$ and $Z_{\mathrm{M}}=0.7682$.

Figure 1c shows the movement curves of ice particles near the upper boundary, which can be sorted by the value of $R_{0}$. For $1<R_{0}<R_{01}$, the neutral drag force increases faster than gravity as the particles fall. The particles decelerate to zero speed, retrace upward, and then leave the condensation layer from the upper boundary. For $R_{0}=R_{01}$, the particles retrace at the height $Z=Z_{1}$, then they arrive at $Z=0$ with exactly zero velocity, and the particles move back into the condensation layer again. For $R_{01}<R_{0}<R_{02}$, the particles retrace upward in the range of $Z_{2}<Z<Z_{1}$ and move downward again before they reach the upper boundary. For $R_{0}=R_{02}$, the particles decelerate downward until zero speed at $Z=Z_{2}$. Here, the acceleration happens to be zero. Then the gravity exceeds the drag force, and the particles accelerate downward. For $R_{0}>R_{02}$, the particles continue moving down after entering the condensation layer. According to the above parameters, $R_{01}$ and $R_{02}$ are solved as 1.1519 and 1.19705 , respectively. 

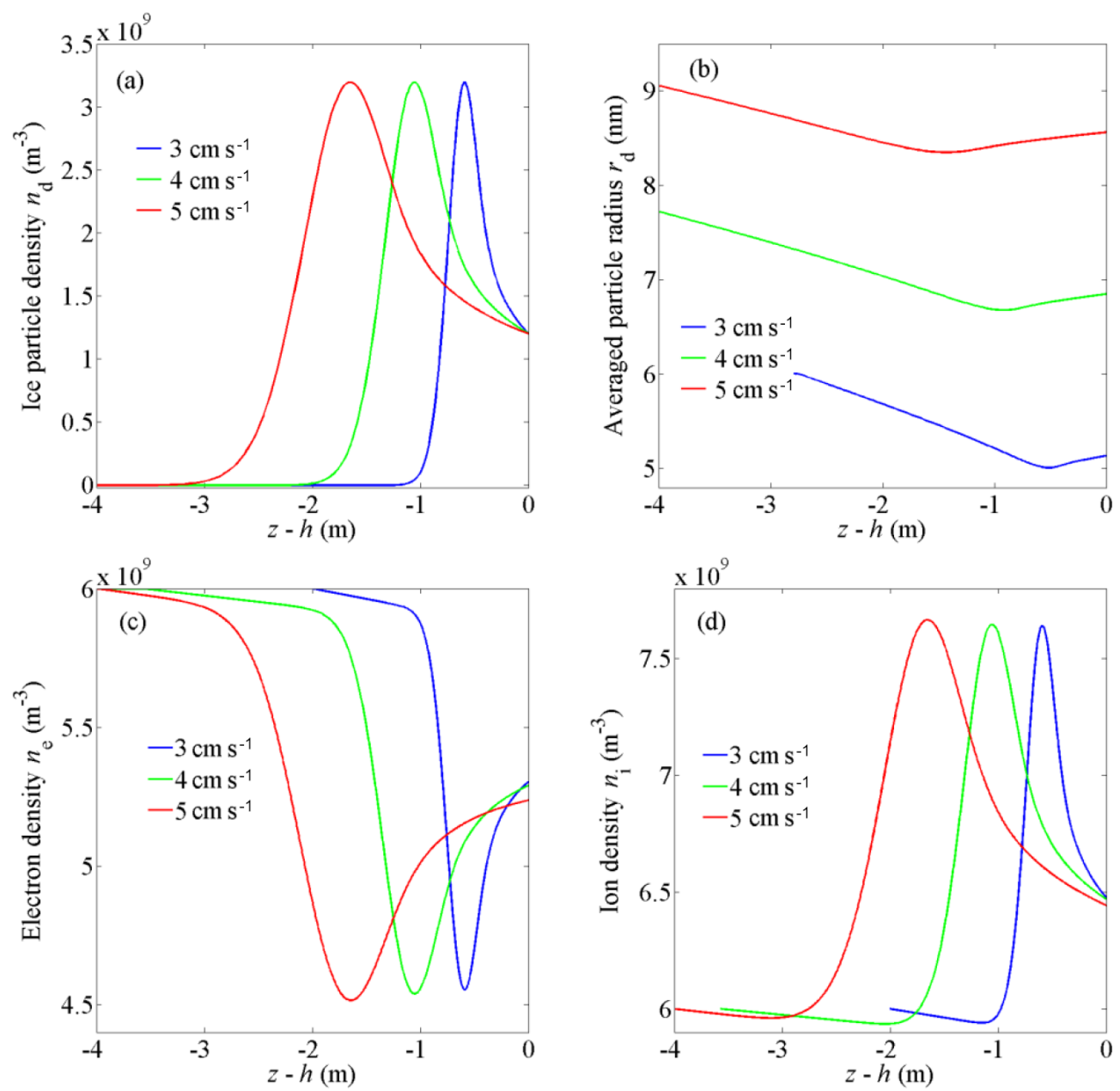

Figure 8. The distribution of (a) ice particle density, (b) the averaged particle radius, (c) electron density, and (d) ion density for various vertical wind speeds near the upper boundary of the condensation layer.

It can be observed in Fig. 1 that the particles with a certain initial radius will move up and down several times near the boundary; namely, ice particles will accumulate at that region and form some kind of small-scale density structure.

\subsection{Density and radius distribution of ice particles and their effects on plasma}

\subsubsection{Near the lower boundary}

The density and radius distribution of ice particles near the lower boundary are first solved. As illustrated in Fig. 1b, all ice particles with an initial radius $R_{0} \leq 1$ will pass the range $0<Z<Z_{\mathrm{m}}$ twice, so they contribute twice to the calculation of particle density. In the height range $Z_{\mathrm{m}}<Z<Z_{\mathrm{M}}$, only the particles that can reach the $Z$ height will contribute to the density at $Z$. The density and mean radius of ice particles near the lower boundary are shown below.

$$
\begin{aligned}
n_{\mathrm{d}}(Z)= & n_{0} \int_{0.5}^{R_{0 Z}} V_{\mathrm{d} 0} F\left(R_{0}\right) \\
& {\left[\frac{1}{V_{\mathrm{d} 1}\left(R_{0}, R_{\mathrm{d} 1}\right)}+\frac{1}{\left|V_{\mathrm{d} 2}\left(R_{0}, R_{\mathrm{d} 2}\right)\right|}\right] \mathrm{d} R_{0}, } \\
\bar{R}_{\mathrm{d}}(Z)= & \frac{n_{0}}{n_{\mathrm{d}}(Z)} \int_{0.5}^{R_{0 Z}} V_{\mathrm{d} 0} F\left(R_{0}\right) \\
& {\left[\frac{R_{\mathrm{d} 1}}{V_{\mathrm{d} 1}\left(R_{0}, R_{\mathrm{d} 1}\right)}+\frac{R_{\mathrm{d} 2}}{\left|V_{\mathrm{d} 2}\left(R_{0}, R_{\mathrm{d} 2}\right)\right|}\right] \mathrm{d} R_{0}, }
\end{aligned}
$$

where $R_{\mathrm{d} 1}$ and $R_{\mathrm{d} 2}$ are particle radii when particles pass through the $Z$ height, $V_{\mathrm{d} 1}$ and $V_{\mathrm{d} 2}$ are the corresponding velocities, and the upper limit of integral $R_{0 Z}$ is determined by

$R_{0 Z}=\left\{\begin{array}{cc}1 & \text { if } Z_{\mathrm{m}}<Z<Z_{\mathrm{M}} \\ \text { solution of }\left(Z\left(R_{0 Z}, R_{\mathrm{d}}\right)=Z\right) & \text { if } 0<Z<Z_{\mathrm{m}}\end{array}\right.$.

In this study, the radius distribution function of condensation cores is assumed to be a Gaussian distribution.

$F\left(R_{0}\right)=A \exp \left[-\left(R_{0}-R_{00}\right)^{2} / \Delta^{2}\right]$, 

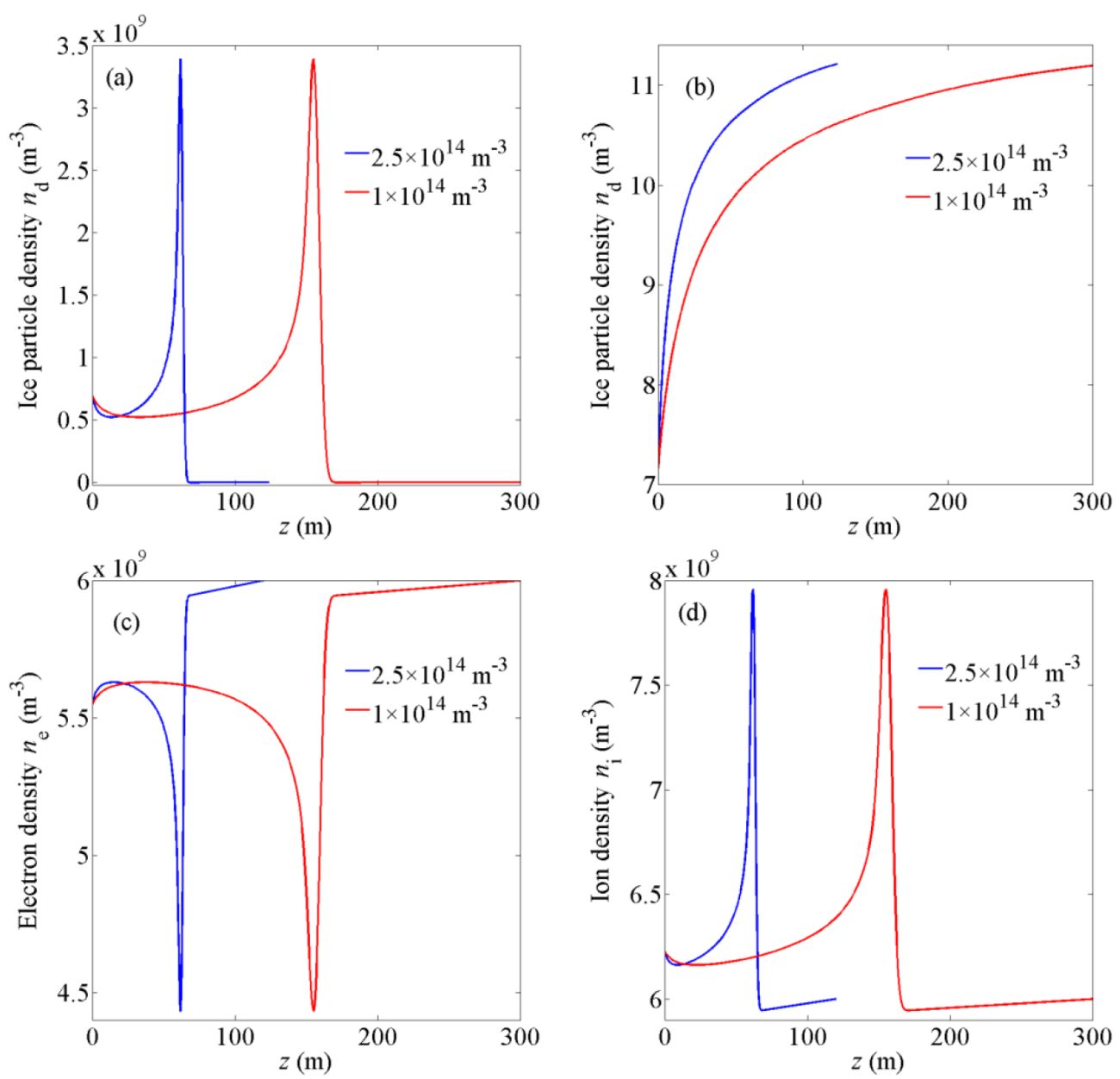

Figure 9. The distribution of (a) ice particle density, (b) the averaged particle radius, (c) electron density, and (d) ion density for various water vapor densities near the lower boundary of the condensation layer.

where the center of the radius distribution function $R_{00}$ is chosen to be 0.8 , the characteristic width is $\Delta=0.01$, and the corresponding normalized coefficient is $A=56.4$.

The obtained density and mean radius of ice particles near the lower boundary are presented in Fig. $2 \mathrm{a}$ and b, respectively. Figure 2a shows that a sharp peak appears in the density distribution of ice particles. The width at the half maximum of the irregularity is about $5 \mathrm{~m}$, which is consistent with the assumed ice particle density structure scale in theoretical work (Lie-Svendsen et al., 2003; Rapp and Lübken, 2003) as well as in the observation by the sounding rocket flight ECT02 in July 1994 (Rapp and Lübken, 2004). In Fig. 2b, it can be observed that the average radius of ice particles increases from 7 to $11 \mathrm{~nm}$ with height.

According to the obtained density and average radius of ice particles in Fig. 2a and b, the density distribution of electrons, ions, and charged ice particles is calculated based on the charging model described by Eqs. (16)-(24). At the initial moment of the charging model, all ice particles are assumed to be neutral in order to conduct the calculation more conveniently, as the final distributions of charge are independent from the initial ice particle charge state (Lie-Svendsen et al., 2003). The timescale of electrons collected by negatively charged particles with a radius of $10 \mathrm{~nm}$ is approximately $700 \mathrm{~s}$, which is the longest timescale in the charging process. The quasi-steady state of charging can then be obtained after this timescale. Therefore, the calculation is terminated after $1000 \mathrm{~s}$, and the results are illustrated in Fig. 3.

Figure 3a shows that electron density decreases sharply around $z=60 \mathrm{~m}$ due to adsorption by particles and the reduction of electron density $\Delta n_{\mathrm{e}} \approx\left(n_{-1}+2 n_{-2}\right) / 2$, which corresponds to the results under diffusion equilibrium approximations in earlier work (Lie-Svendsen et al., 2003). Ion number density increases sharply around $60 \mathrm{~m}$ due to diffusion under the ambipolar electric field. The ambipolar diffusion process of electrons and ions has been described in detail in previous work (Lie-Svendsen et al., 2003). Electron density is anticorrelated to density irregularities of ions and the charged ice particles due to the attachment and diffusion processes. The anti-correlations correspond with rocket observations 

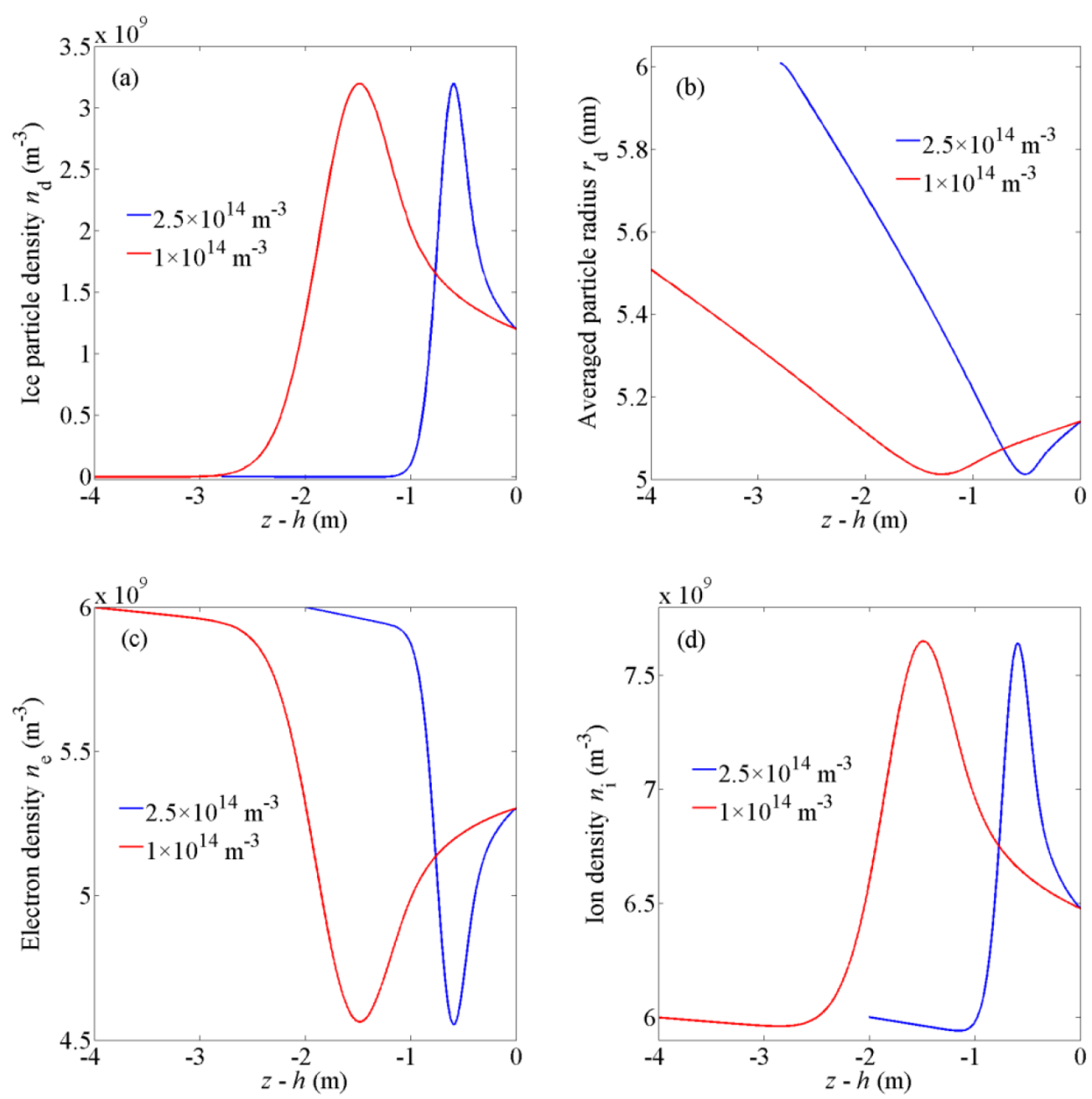

Figure 10. The distribution of (a) ice particle density, (b) the averaged particle radius, (c) electron density, and (d) ion density for various water vapor densities near the upper boundary of the condensation layer.

by the sounding rocket flight SCT-06 in August 1993 (LieSvendsen et al., 2003) and the sounding rocket flight ECT02 in July 1994 (Rapp and Lübken, 2004). According to Fig. 3c and $\mathrm{d}$, it can be determined that for particles with radii ranging from 7 to $11 \mathrm{~nm}$, the proportion of particles carrying one negative charge ranges from $97.5 \%$ to $85.1 \%$, and the value for particles carrying two negative charges is $0.53 \%-13.6 \%$, which is consistent with observations by Havnes et al. (1996) and numerical results by Rapp and Lübken (2001). The density of positively charged particles is less than $1.1 \times 10^{5} \mathrm{~m}^{-3}$ and is insignificant in this study.

\subsubsection{Near the upper boundary}

The parameters of ice particles and plasma near the upper boundary are discussed in this subsection, based on the movement curves of ice particles near the upper boundary, as shown in Fig. 4.
For $Z_{1}<Z<0$, particles with an initial radius $R_{0 Z 1}$ and $R_{0 Z 2}$ turn back at $Z$ and move upward and downward separately, as shown in Fig. 4. The values of $R_{0 Z 1}$ and $R_{0 Z 2}$ are determined by the equations $V_{\mathrm{d}}\left(R_{0 Z}, R_{\mathrm{d}}\right)=0$ and $Z\left(R_{0 Z}, R_{\mathrm{d}}\right)=Z$. The contribution of ice particles to the density distribution near the upper boundary can be classified as follows:

1. $R_{0}<R_{0 Z 1}$ : ice particles cannot reach $Z$ and make no contributions to the number density.

2. $R_{0 Z 1}<R_{0}<R_{01}$ : ice particles pass through $Z$ twice and contribute to $n_{\mathrm{d}}(Z)$ twice. The radius of particles when passing through the $Z$ height can be obtained as $R_{d 31}$ and $R_{\mathrm{d} 32}$ based on Eq. (27). Their corresponding velocities are calculated respectively as $V_{\mathrm{d} 31}$ and $V_{\mathrm{d} 32}$ based on Eq. (25). 

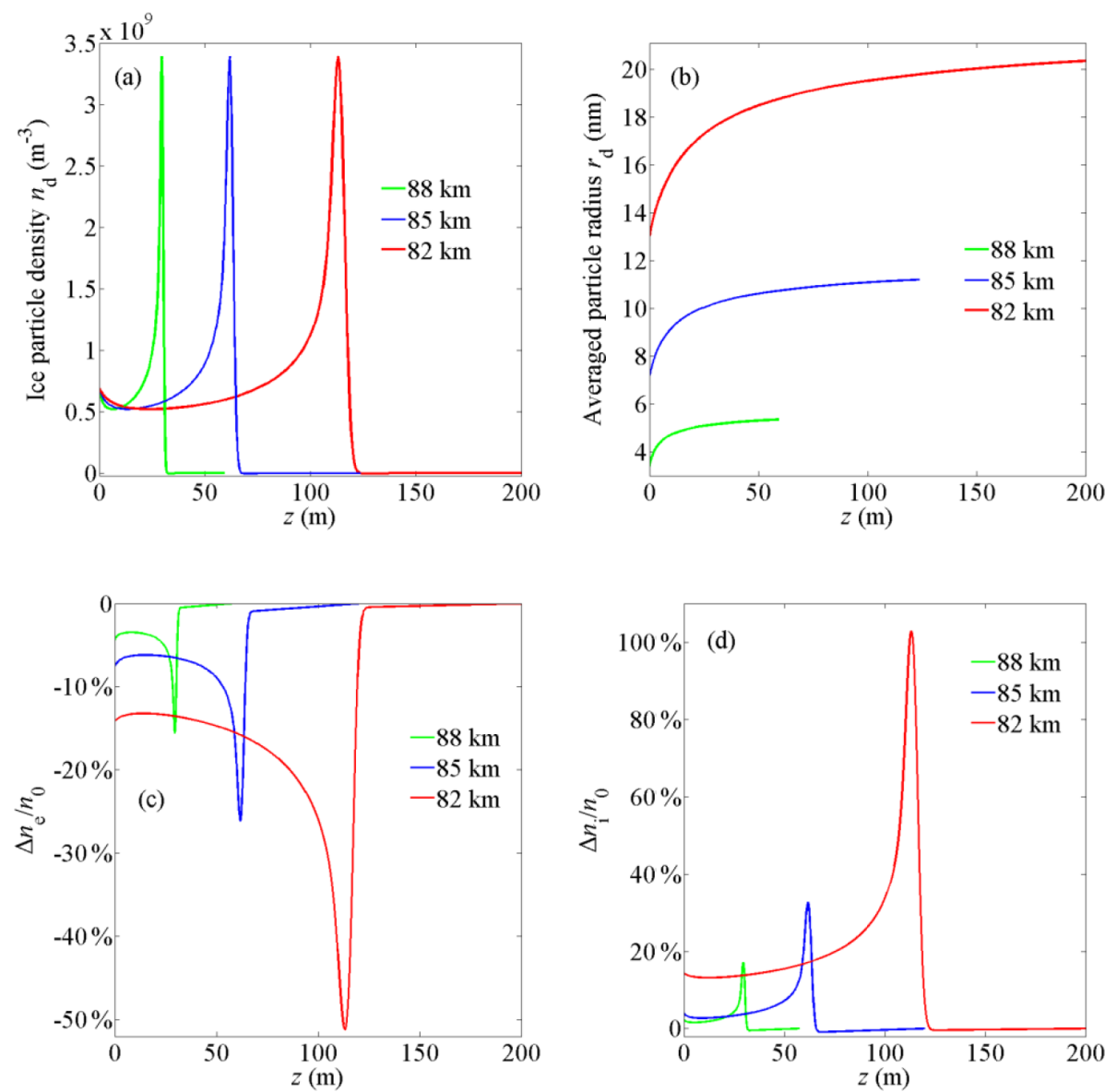

Figure 11. The distribution of (a) ice particle density, (b) the averaged particle radius, (c) the relative change of electron density $\Delta n_{\mathrm{e}} / n_{\mathrm{e}}$, and (d) the relative change of ion density $\Delta n_{\mathrm{i}} / n_{\mathrm{i}}$ at various altitudes near the lower boundary of the condensation layer.

3. $R_{01}<R_{0}<R_{0 Z 2}$ : ice particles pass through $Z$ three times. The corresponding radii and velocities at $Z$ are defined as $R_{\mathrm{d} 41}, R_{\mathrm{d} 42}$, and $R_{\mathrm{d} 43}$ and $V_{\mathrm{d} 41}, V_{\mathrm{d} 42}$, and $V_{\mathrm{d} 43}$.

4. $R_{0}>R_{0 Z 2}$ : ice particles pass through $Z$ only once, and their radius and velocity are $R_{\mathrm{d} 5}$ and $V_{\mathrm{d} 5}$, respectively.

Substituting these parameters into Eqs. (28) and (29), the density and mean radius of ice particles in the range $Z_{1}<Z<0$ are deduced as

$$
\begin{aligned}
n_{\mathrm{d}}(Z) & =n_{0} \int_{R_{0 Z Z}}^{R_{01}}\left|V_{\mathrm{d} 0}\right| F\left(R_{0}\right) \\
& {\left[\frac{1}{\left|V_{\mathrm{d} 31}\left(R_{0}, R_{\mathrm{d} 31}\right)\right|}+\frac{1}{V_{\mathrm{d} 32}\left(R_{0}, R_{\mathrm{d} 32}\right)}\right] \mathrm{d} R_{0} } \\
& +n_{0} \int_{R_{01}}^{R_{0 \mathrm{Z}}}\left|V_{\mathrm{d} 0}\right| F\left(R_{0}\right) \\
& {\left[\frac{1}{\left|V_{\mathrm{d} 41}\left(R_{0}, R_{\mathrm{d} 41}\right)\right|}+\frac{1}{V_{\mathrm{d} 42}\left(R_{0}, R_{\mathrm{d} 42}\right)}\right.} \\
& \left.+\frac{1}{\mid V_{\mathrm{d} 43}\left(R_{0}, R_{\mathrm{d} 433)}\right)}\right] \mathrm{d} R_{0} \\
& +n_{0} \int_{R_{0 Z 2}}^{R_{0} \max } \frac{\left|V_{\mathrm{d} 0}\right| F\left(R_{0}\right)}{\left|V_{\mathrm{d} 5}\left(R_{0}, R_{\mathrm{d} 5}\right)\right|} \mathrm{d} R_{0}
\end{aligned}
$$

$$
\begin{aligned}
\bar{R}_{\mathrm{d}}(Z) & =\frac{n_{0}}{n_{\mathrm{d}}(Z)} \int_{R_{0 Z 1}}^{R_{01}}\left|V_{\mathrm{d} 0}\right| F\left(R_{0}\right) \\
& {\left[\frac{R_{\mathrm{d} 31}}{\left|V_{\mathrm{d} 31}\left(R_{0}, R_{\mathrm{d} 31}\right)\right|}+\frac{R_{\mathrm{d} 32}}{V_{\mathrm{d} 32}\left(R_{0}, R_{\mathrm{d} 32}\right)}\right] \mathrm{d} R_{0} } \\
& +\frac{n_{0}}{n_{\mathrm{d}}(Z)} \int_{R_{01}}^{R_{02}}\left|V_{\mathrm{d} 0}\right| F\left(R_{0}\right) \\
& {\left[\frac{R_{\mathrm{d} 41}}{\mid V_{\mathrm{d} 41}\left(R_{0}, R_{\mathrm{d} 41)}\right)}+\frac{R_{\mathrm{d} 42}}{V_{\mathrm{d} 42}\left(R_{0}, R_{\mathrm{d} 42}\right)}\right.} \\
& \left.+\frac{R_{\mathrm{d} 43}}{\mid V_{\mathrm{d} 43}\left(R_{0}, R_{\mathrm{d} 43)}\right)}\right] \mathrm{d} R_{0} \\
& +\frac{n_{0}}{n_{\mathrm{d}}(Z)} \int_{R_{02} \max }^{R_{02}} \frac{R_{\mathrm{d} 5}\left|V_{\mathrm{d} 0}\right| F\left(R_{0}\right)}{\left|V_{\mathrm{d} 5}\left(R_{0}, R_{\mathrm{d} 5}\right)\right|} \mathrm{d} R_{0}
\end{aligned} .
$$

The center of the radius distribution function is $R_{00}=1.08$; the characteristic width is $\Delta=0.01$; and the corresponding normalized coefficient is $A=56.4$.

The ice particle density in the region of $Z<Z_{1}$ is close to zero, as only particles with an initial radius $R_{0} \geq R_{01}$ can arrive at the region, and the number of the particles in this radius range is very low based on the radius distribution function set above.

At the upper boundary, the number density of condensation cores $n_{0}$ is set as $5 \times 10^{8} \mathrm{~m}^{-3}$, and the maximum radius of condensation cores is $R_{0 \max }=1.3$. The number density and mean radius of ice particles are obtained from Eqs. (34) and (35) and are shown in Fig. 5. The density distribution of 

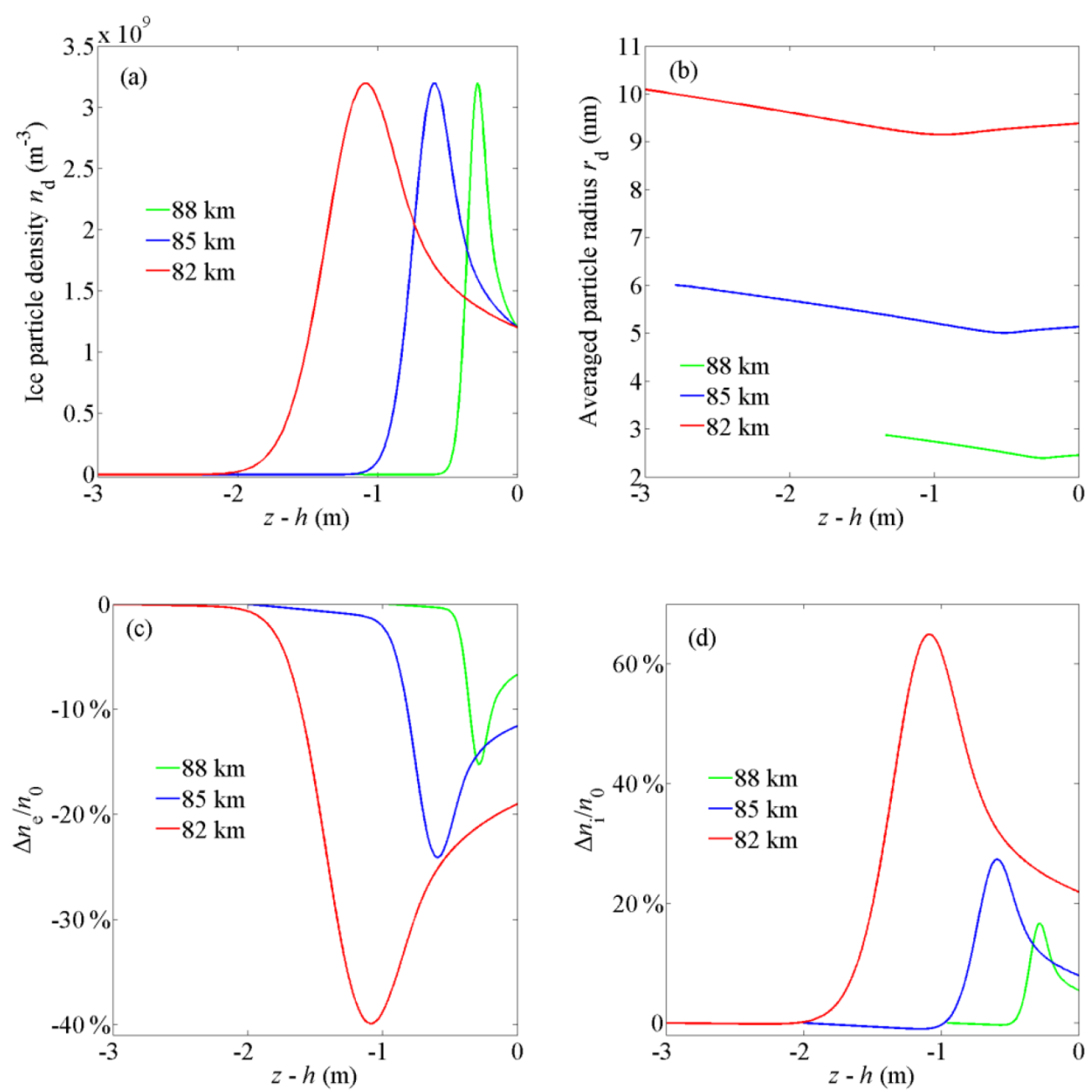

Figure 12. The distribution of (a) ice particle density, (b) the averaged particle radius, (c) the relative change of electron density $\Delta n_{\mathrm{e}} / n_{\mathrm{e}}$, and (d) the relative change of ion density $\Delta n_{\mathrm{i}} / n_{\mathrm{i}}$ at various altitudes near the upper boundary of the condensation layer.

electrons, ions, and charged ice particles is then calculated further based on the charging model.

Figure 5a shows that there is a meter scale structure in the distribution of ice particle density, which is consistent with the assumed ice particle density structure scale in previous theoretical work (Lie-Svendsen et al., 2003; Rapp and Lübken, 2003) and rocket observations (Rapp and Lübken, 2004). In addition, the average radius of ice particles is slightly larger than $5 \mathrm{~nm}$ (shown in Fig. 5b).

As illustrated in Fig. 6a, compared with ice particle density, there is a similar but anti-correlated structure in the electron density profile because of the adsorption of electrons by particles. Due to ambipolar diffusion, ion density increases in the perturbed region. The reduction of electron density $\Delta n_{\mathrm{e}}$ and the increment of ion density $\Delta n_{\mathrm{i}}$ are consistent with the results under diffusion equilibrium approximations: $\Delta n_{e} \approx \Delta n_{\mathrm{i}} \approx\left(n_{-1}+2 n_{-2}\right) / 2$ (Lie-Svendsen et al., 2003). According to Fig. $6 \mathrm{c}$ and d, $97 \%$ of the particles carry one negative charge, and few particles carry two negative charges. This is reasonable for particles with a radius slightly larger than $5 \mathrm{~nm}$.

\subsection{Influence of the vertical wind speed on the spatial scale of the irregularities}

The vertical wind speed is varied from 3 to $5 \mathrm{~cm} \mathrm{~s}^{-1}$ to investigate the influence of the wind speed on the spatial scale of the irregularities. With all other parameters remaining the same, the numerical results are shown in Figs. 7 and 8. When the wind speed is increased, the spatial scale of the irregularities increases as higher wind speed corresponds to a larger critical particle radius $r_{\mathrm{c}}$ in the growth model (see Eq. 9). This leads to a longer timescale $\left(t_{\mathrm{c}}\right)$ and larger spatial scale $\left(z_{\mathrm{c}}\right)$ of ice particle growth and movement. In addition, as shown in Fig. 7c and d, with the increase of wind speed, the variation amplitude of electron density and ion density near the lower boundary obviously increases. This is because the averaged radius of the ice particles increases with the exten- 
sion of the particle growth time (see Fig. 7b), and the particles' influence on the plasma increases. The variation amplitude of electron density and ion density near the upper boundary does not notably change (see Fig. $8 \mathrm{c}$ and d) because there is little variation in the averaged radii of the ice particles for different wind speeds, as shown in Fig. 8b.

\subsection{Influence of the water vapor density on the spatial scale of the irregularities}

Water vapor density can also affect the spatial scale of the particle density structures by modifying the change rate of the particle radius. As illustrated in Figs. 9 and 10, the spatial scale of the irregularities decreases when the water vapor density increases. A larger vapor density results in a higher change rate of the particle radius (see Eq. 10) and a shorter timescale $\left(t_{\mathrm{c}}\right)$ of ice particle growth. The particles can then reach the inversion condition more quickly, and the reverse position is closer to the boundary, meaning that the spatial scale of the ice particle density structures becomes shorter.

\subsection{Influence of the altitude on the irregularities spatial scale}

The effect of the altitude on the spatial scale of the irregularities is explored in this subsection. The altitude mainly affects the neutral gas density $n_{\mathrm{n}}$, ion composition, ion mass $m_{\mathrm{i}}$, production rate for plasma $Q$, electron-ion recombination coefficient $\alpha$, and plasma density $n_{0}$ without ice particles. In addition to $85 \mathrm{~km}$, altitudes of 82 and $88 \mathrm{~km}$ are also included as they are near the lower and upper limits of the PMSE region (Lie-Svendsen et al., 2003). According to previous work (Blix, 1999; Lübken, 1999; Rapp and Lübken, $2001)$, at $82 \mathrm{~km}$, the positive ions are mainly $\left(\mathrm{H}_{3} \mathrm{O}\right)^{+}\left(\mathrm{H}_{2} \mathrm{O}\right)_{3}$ cluster ions with $m_{\mathrm{i}}=73 m_{u}$, and other parameters are set as $n_{n}=4.2 \times 10^{20} \mathrm{~m}^{-3}, Q=6.3 \times 10^{7} \mathrm{~m}^{-3} \mathrm{~s}^{-1}, \alpha=7 \times$ $10^{-12} \mathrm{~m}^{3} \mathrm{~s}^{-1}$, and $n_{0}=3 \times 10^{9} \mathrm{~m}^{-3}$. At $88 \mathrm{~km}$ altitude, the positive ions are mainly $\mathrm{NO}^{+}$with $m_{\mathrm{i}}=30 m_{u}$, and other parameters are $n_{\mathrm{n}}=1.1 \times 10^{20} \mathrm{~m}^{-3}, Q=6 \times 10^{7} \mathrm{~m}^{-3} \mathrm{~s}^{-1}$, $\alpha=6 \times 10^{-13} \mathrm{~m}^{3} \mathrm{~s}^{-1}$, and $n_{0}=1 \times 10^{10} \mathrm{~m}^{-3}$. The numerical results are provided in Figs. 11 and 12. As the ambient plasma density $n_{0}$ varies dramatically at different altitudes, the electron density relative change $\Delta n_{\mathrm{e}} / n_{\mathrm{e}}$ and the ion density relative change $\Delta n_{\mathrm{i}} / n_{\mathrm{i}}$ are calculated for comparison, where $\Delta n_{\mathrm{e}}=n_{\mathrm{e}}-n_{0}$ and $\Delta n_{\mathrm{i}}=n_{\mathrm{i}}-n_{0}$. Figures 11a and 12a show that with the increase in altitude, the spatial scale of the ice particle density irregularities becomes shorter. The reason for this finding is that higher altitudes correspond to a smaller neutral density $n_{n}$ and critical particle radius $r_{\mathrm{c}}$ (see Eq. 9), which leads to a shorter timescale $\left(t_{\mathrm{c}}\right)$ and spatial scale $\left(z_{\mathrm{c}}\right)$ of ice particle growth and movement. It is notable that the spatial scale of the electron density irregularities at lower altitudes is longer than that at higher altitudes (see Figs. 11c and 12c). This result is consistent with the explanation provided by Bremer et al. that at lower altitudes the PMSE signals de- tected by long-wavelength radar (half wavelength of $54 \mathrm{~m}$ ) are stronger than those detected by short-wavelength radar (half wavelength of $2.8 \mathrm{~m}$ ) (Bremer et al., 1997). In addition, with the increase of altitude, the relative change amplitude of electron density and ion density decreases significantly because the averaged radius of the ice particles at higher altitudes is smaller, and the influence of ice particles on plasma decreases.

\section{Conclusions}

In this paper, a growth and motion model of ice particles was developed based on the equation of variable mass object motion in order to explain the formation of ice particle density irregularities with a meter scale in the polar mesopause region. The density profile of ice particles with height was investigated according to the conservation of the particle number. Based on the growth and motion model, small-scale structures of ice particle density were successfully produced. The density distributions of electrons and ions corresponding to the ice particle density distribution were then obtained based on quasi-neutrality and the discrete charging model. The findings are summarized as follows.

The ice particle radius increases linearly with time. However, a complex relation occurs between the velocity and radius of particles due to the variable mass of ice particles and the complicated force operating on them. For a certain radius of the condensation nucleus, ice particles can bounce near the boundary layer, which leads to a local gathering phenomenon of ice particles and the creation of meter scale ice particle density structures. The spatial scale of the density structures can be affected by vertical wind speed, water vapor density, and altitude. The spatial scale increases with the increase of wind speed, and it decreases with the increase of water vapor density and altitude. Small-scale ice particle density irregularities can remain stable if these atmospheric conditions do not change. In the ice particle gathering region, the electron density is anti-correlated to the charged ice particle density and the ion density because of the plasma attachment by ice particles and plasma diffusion. To summarize, small-scale ice particle density irregularities are formed and maintained in the polar mesopause region based on the growth and motion model, and the corresponding small-scale electron density structures are in accordance with most rocket observations.

Data availability. No data sets were used in this article.

Author contributions. JM and JW put forward the idea. JM and RT developed the model. RT created the model. YL created the figures. $\mathrm{HL}$ analyzed the data. RT and CY wrote the paper. YJ and ZZ revised the paper. 
Competing interests. The authors declare that they have no conflict of interest.

Acknowledgements. The research has been financially supported by the National Natural Science Foundation of China under (grant nos. 11775062 and 61601419) and the Key Laboratory Foundation of the National Key Laboratory of Electromagnetic Environment (grant no. 614240319010303).

Financial support. The research has been supported by the National Natural Science Foundation of China (grant nos. 11775062 and 61601419) and the Key Laboratory Foundation of the National Key Laboratory of Electromagnetic Environment (grant no. 614240319010303).

Review statement. This paper was edited by Andrew J. Kavanagh and reviewed by two anonymous referees.

\section{References}

Bardeen, C., Toon, O., Jensen, E., Marsh, D., and Harvey, V.: Numerical simulations of the three-dimensional distribution of meteoric dust in the mesosphere and upper stratosphere, J. Geophys. Res.-Atmos., 113, D17202, https://doi.org/10.1029/2007JD009515, 2008.

Blix, T.: Small scale plasma and charged aerosol variations and their importance for polar mesosphere summer echoes, Adv. Space Res., 24, 537-546, 1999.

Bremer, J., Hoffmann, P., Manson, A. H., Meek, C. E., Rüster, R., and Singer, W.: PMSE observations at three different frequencies in northern Europe during summer 1994, Ann. Geophys., 14, 1317-1327, https://doi.org/10.1007/s00585-996-1317-7, 1996.

Chen, C. and Scales, W.: Electron temperature enhancement effects on plasma irregularities associated with charged dust in the Earth's mesosphere, J. Geophys. Res.-Space, 110, A12313, https://doi.org/10.1029/2005JA011341, 2005.

Garcia, R. R. and Solomon, S.: The effect of breaking gravity waves on the dynamics and chemical composition of the mesosphere and lower thermosphere, J. Geophys. Res.-Atmos., 90, 38503868, 1985.

Havnes, O., Trøim, J., Blix, T., Mortensen, W., Næsheim, L., Thrane, E., and Tønnesen, T.: First detection of charged dust particles in the Earth's mesosphere, J. Geophys. Res.-Space, 101, 10839-10847, 1996.

Hill, R. and Bowhill, S.: Collision frequencies for use in the continuum momentum equations applied to the lower ionosphere, J. Atmos. Terr. Phys., 39, 803-811, 1977.

Hill, R., Gibson-Wilde, D., Werne, J., and Fritts, D.: Turbulenceinduced fluctuations in ionization and application to PMSE, Earth Planet. Space, 51, 499-513, 1999.

Jensen, E. and Thomas, G. E.: A growth-sedimentation model of polar mesospheric clouds: Comparison with SME measurements, J. Geophys. Res.-Atmos., 93, 2461-2473, 1988.
Kopnin, S., Kosarev, I., Popel, S., and Yu, M.: Localized structures of nanosize charged dust grains in Earth's middle atmosphere, Planet. Space Sci., 52, 1187-1194, 2004.

Körner, U. and Sonnemann, G.: Global three-dimensional modeling of the water vapor concentration of the mesosphere-mesopause region and implications with respect to the noctilucent cloud region, J. Geophys. Res.-Atmos., 106, 9639-9651, 2001.

Lie-Svendsen, Ø., Blix, T., Hoppe, U. P., and Thrane, E.: Modeling the plasma response to small-scale aerosol particle perturbations in the mesopause region, J. Geophys. Res.-Atmos., 108, 8442, https://doi.org/10.1029/2002JD002753, 2003.

Lieberman, M. A. and Lichtenberg, A. J.: Principles of plasma discharges and materials processing, John Wiley \& Sons, 733 pp., 2005.

Lübken, F. J.: Thermal structure of the Arctic summer mesosphere, J. Geophys. Res.-Atmos., 104, 9135-9149, 1999.

Lübken, F. J., Rapp, M., Blix, T., and Thrane, E.: Microphysical and turbulent measurements of the Schmidt number in the vicinity of polar mesosphere summer echoes, Geophys. Res. Lett., 25, 893896, 1998.

Mahmoudian, A. and Scales, W.: On the signature of positively charged dust particles on plasma irregularities in the mesosphere, J. Atmos. Sol.-Terr. Phys., 104, 260-269, 2013.

Natanson, G.: On the theory of the charging of amicroscopic aerosol particles as a result of capture of gas ions, Sov. Phys. Tech. Phys., 30, 573-588, 1960.

Pfaff, R., Holzworth, R., Goldberg, R., Freudenreich, H., Voss, H., Croskey, C., Mitchell, J., Gumbel, J., Bounds, S., and Singer, W.: Rocket probe observations of electric field irregularities in the polar summer mesosphere, Geophys. Res. Lett., 28, 1431-1434, 2001.

Rapp, M. and Lübken, F.-J.: Modelling of particle charging in the polar summer mesosphere: Part 1 - General results, J. Atmos. Sol.-Terr. Phys., 63, 759-770, 2001.

Rapp, M. and Lübken, F. J.: On the nature of PMSE: Electron diffusion in the vicinity of charged particles revisited, J. Geophys. Res.-Atmos., 108, 8437, https://doi.org/10.1029/2002JD002857, 2003.

Rapp, M. and Lübken, F.-J.: Polar mesosphere summer echoes (PMSE): Review of observations and current understanding, Atmos. Chem. Phys., 4, 2601-2633, https://doi.org/10.5194/acp-42601-2004, 2004.

Reid, G. C.: Ice particles and electron "bite-outs" at the summer polar mesopause, J. Geophys. Res.-Atmos., 95, 13891-13896, 1990.

Robertson, S. and Sternovsky, Z.: Effect of the induced-dipole force on charging rates of aerosol particles, Phys. Plasmas, 15, 040702, https://doi.org/10.1063/1.2907162, 2008.

Röttger, J., La Hoz, C., Kelley, M. C., Hoppe, U., and Hall, C.: The structure and dynamics of polar mesosphere summer echoes observed with the EISCAT $224 \mathrm{MHz}$ radar, Geophys. Res. Lett., 15, 1353-1356, 1988.

Röttger, J., Rietveld, M., La Hoz, C., Hall, T., Kelley, M., and Swartz, W.: Polar mesosphere summer echoes observed with the EISCAT $933 \mathrm{MHz}$ radar and the CUPRI $46.9 \mathrm{MHz}$ radar, their similarity to $224 \mathrm{MHz}$ radar echoes, and their relation to turbulence and electron density profiles, Radio Sci., 25, 671-687, 1990. 
Scales, W. and Ganguli, G.: Investigation of plasma irregularity sources associated with charged dust in the Earth's mesosphere, Adv. Space Res., 34, 2402-2408, 2004.

Schunk, R.: Mathematical structure of transport equations for multispecies flows, Rev. Geophys., 15, 429-445, 1977.
Seele, C. and Hartogh, P.: Water vapor of the polar middle atmosphere: Annual variation and summer mesosphere conditions as observed by ground-based microwave spectroscopy, Geophys. Res. Lett., 26, 1517-1520, 1999. 